Bond University

Research Repository

\title{
Casino customers in Asian versus western gaming jurisdictions
}

\section{Implications for western casino operators}

Kale, Sudhir H.; Spence, Mark T.

Published in:

Worldwide Hospitality and Tourism Themes

DOI:

$10.1108 / 17554210911002165$

Licence:

Other

Link to output in Bond University research repository.

Recommended citation(APA):

Kale, S. H., \& Spence, M. T. (2009). Casino customers in Asian versus western gaming jurisdictions:

Implications for western casino operators. Worldwide Hospitality and Tourism Themes, 1(4), 320-331.

https://doi.org/10.1108/17554210911002165

\section{General rights}

Copyright and moral rights for the publications made accessible in the public portal are retained by the authors and/or other copyright owners and it is a condition of accessing publications that users recognise and abide by the legal requirements associated with these rights.

For more information, or if you believe that this document breaches copyright, please contact the Bond University research repository coordinator 


\title{
Bond University
}

\section{ePublications@bond}

1-1-2009

\section{Casino customers in Asian versus Western gaming jurisdictions: Implications for Western casino operators}

\author{
Sudhir H. Kale \\ Bond University, sudhir_kale@bond.edu.au \\ Mark Spence \\ Bond University, mark_spence@bond.edu.au
}

Follow this and additional works at: http://epublications.bond.edu.au/business_pubs

Part of the Hospitality Administration and Management Commons, International Business Commons, and the Marketing Commons

\section{Recommended Citation}

Sudhir H. Kale and Mark Spence. (2009) "Casino customers in Asian versus Western gaming jurisdictions: Implications for Western casino operators" Worldwide hospitality and tourism themes: How can casino gaming be used to maximize the benefits for tourism destinations?, 1 (4), 320-331.

http://epublications.bond.edu.au/business_pubs/230

This Journal Article is brought to you by the Bond Business School at ePublications@bond. It has been accepted for inclusion in Bond Business School Publications by an authorized administrator of ePublications@bond. For more information, please contact Bond University's Repository Coordinator. 


\section{Casino Customers in Asian versus Western Gaming Jurisdictions: Implications for Western Casino Operators}

By

Sudhir H. Kale* and Mark T. Spence**

*Sudhir H. Kale is Professor of Marketing and Co-Director of the Globalisation and Development Centre at Bond University, Gold Coast, QLD 4229, Australia (E-mail: skale@bond.edu.au). He is also Founder and President of GamePlan Consultants (www.gameplanconsultants.com).

**Mark Spence is Associate Professor of Marketing and Ph.D. Program Director in the School of Business at Bond University, Gold Coast, Australia (E-mail: mspence@bond.edu.au).

Address correspondence to Sudhir Kale. 


\section{Casino Customers in Asian versus Western Gaming Jurisdictions: Implications for Western Casino Operators}

\section{Purpose}

Most of the growth in casino expansion for the foreseeable future will take place in Asia. Western casino operators appreciate the immense opportunities afforded by the Asian markets, but judging by their performance abroad some have not adapted in ways necessary to survive and prosper. This paper exposes key differences between Asian and Western gaming jurisdictions. In light of these differences, it is a serious mistake for Western casino executives to follow an ethnocentric approach when planning marketing activities and customer service initiatives for Asian customers. To rectify this situation, a framework is advanced that will assist Western operators to adapt to Asian markets.

\section{Approach}

Differences between Asian and Western gamblers in both their game preferences and behaviours are based upon cited data sources and upon the authors' observations during flied trips to various casino jurisdictions. When appropriate, insights gleaned from a series of informal interviews conducted with senior executives in Macau as well as gaming related consulting conducted by the authors in both Asia and North America are shared, albeit for legal reasons the sources are confidential. The TROPICS framework presented herein was developed by the lead author and presented to senior gaming executives at the University of Nevada, Reno 2008 executive development program. The seven elements of this framework - now refined - are targeting, retention, organization, people, incentives, culture, and systems.

\section{Practical implications}

We raise a series of questions and issues related to each of the seven elements in the TROPICS framework. The proposed framework is equally applicable to firms operating in Western countries as well as those in Asia; however, when put into practice the outcome will be different marketing strategies adapted to each casino’s market structure and macro-environment. Regardless of context, this systematic approach to strategy formulation will ensure consistency and alignment across various elements of strategy.

Conceptual paper: Casino marketing, cultural differences, TROPICS framework, Macau 
As of 2007, nearly half the casinos in the world were located in the U.S., and the U.S. also accounted for a majority of gaming revenues (\$34.1 billion). This picture is fast changing, particularly since 2003, when the Macau Provincial Government decided to open up the gaming industry in the former Portuguese colony to foreign competition. According to a 2008 survey conducted by the American Gaming Association, Asia may surpass the United States in casino gambling revenue by 2012, with growth driven by Macau, Singapore, and sites currently being considered in other Asian countries.

Macau has amply demonstrated the enormous market potential for casinos in Asian markets. In less than three years after foreign operators started operating in the region, the gaming revenues have surpassed \$10 billion, thus dwarfing the status of Las Vegas as the world’s gaming Mecca. Macau has also demonstrated stark contrasts in the contribution of various revenue streams compared to the markets in the U.S., Europe, Australia, and South Africa. These differences originate from the preferences of clientele frequenting the casinos.

While foreign casino companies are eagerly seeking licenses to operate in Asian jurisdictions, senior management positions within these organizations are typically staffed by expatriates with little or no international experience. This lack of exposure naturally limits their understanding of the Asian customer mindset. “Cultural distance” has been shown to adversely affect firm performance (Johnson and Tellis, 2008), yet many senior casino executives from Western background tend to assume that over time, all casino markets in the world will resemble Las Vegas.

This paper exposes key differences in the markets of Asia and those located in traditional Western jurisdictions. We argue that it is a serious mistake for Western casino executives to follow an ethnocentric approach when planning marketing activities and customer service initiatives for Asian customers. To rectify this shortcoming we advance a framework for casino 
marketing in Asia. This exercise, pertaining to product adaptation as opposed to standardization, should be of interest to scholars in gaming as well as to marketing practitioners. Western casino executives, desirous of expanding into the fast growing casino markets of Asia should find this discussion particularly relevant.

\section{EAST IS EAST...}

In his landmark provocative article, “The Globalization of Markets,” Ted Levitt (1983) wrote, “The transforming winds whipped up by the proletarianization of communication and travel enter every crevice of life. Commercially, nothing confirms this as much as the success of McDonald's from the Champs Elysées to the Ginza, of Coca Cola in Bahrain and Pepsi Cola in Moscow, and of rock music, Greek salad, Hollywood movies, Revlon cosmetics, Sony televisions and Levi jeans everywhere.” Now, twenty-five years later, even some of Levitt's strongest proponents concede that the "new" global reality that Levitt foresaw never did manifest itself, at least not to any great extent.

The casino industry is one where stark contrasts in customer behavior are evident between the West and the East, and where globalization is probably least apparent. Some Western casino operators such as Las Vegas Sands (LVS) have taken the position that it is only a matter of time before integrated resort properties in Macau, Singapore and other Asian markets will emulate the ambience and revenue mix of Las Vegas. Consequently, the company has invested over \$6 billion in Macau and Singapore alone, betting on the convergence of casino markets between Asia and the U.S. However, a critical analysis of gaming products, revenue streams, and consumer gaming preferences in casino jurisdictions in Asia suggests quite the opposite. If foreign casino operators are to capitalize on the huge market potential in Asia, they will need to adapt their marketing strategy to accommodate the differences in market conditions and 
consumer behavior. Choice of games and property revenue mix in Western markets vis-à-vis Asia will help establish our case.

Slots and Table Games. In stark contrast to North America and Europe, table games in Macau generate the overwhelming majority of casino gaming revenue. Figures from the first quarter of 2008 indicate that there were 4,311 gaming tables and 13,552 slot machines in Macau. Slots generated total revenues of MOP 1.35 billion, out of total revenues of just under MOP 30 billion (MOP $8.17=$ US\$1), accounting for only about 4.5 percent of the total gaming revenues in Macau (Gaming Inspection and Coordination Bureau, Macau SAR).

These figures are strikingly different from most Western markets. Consider Nevada: for the month ended April 30, 2008, the State of Nevada had 4,902 tables and 171,242 slots (Nevada State Gaming Control Board, 2008). During this period, table games revenues for Nevada were \$286 million and slots revenues totaled \$671 million. Slots therefore accounted for almost 70 percent of Nevada's gaming revenues. Also, looking at supply figures, while the table to slot ratio is 1:3 for Macau, it is around 1:35 for Nevada. Slots outnumber tables 10:1 in Australia, 6:1 in Malaysia (Genting Highlands), and 7:1 in South Korea (Siu and Eadington, 2008; Siu and Carman, 2003). Clearly, while slots contribute disproportionately to gaming revenue in the Western markets, table games dominate in the Asian markets.

Siu and Eadington (2008) also report the average annual gaming revenue per table across different countries. For the year ended 2006 the average table in Macau yielded US\$2.7 million in revenue. Corresponding figures in other jurisdictions were \$0.71 million in Nevada, \$0.92 million in Australia, and \$6.00 million in South Korea. These numbers further underscore the table-centric orientation in Asian casinos.

Comparing the casinos in Nevada with those in Macau also sheds light on differences in revenue composition within the category of table games. In Nevada, during the month of April 
2008, Blackjack alone accounted for $\$ 123$ million or 43 percent of table game revenues while Baccarat and Mini-Baccarat together accounted for around 23 percent. In Macau, for the first quarter of 2008, Baccarat provided MOP26.2 billion in revenues whereas Blackjack accounted for just over MOP0.6 billion. Revenues from Baccarat and its variants (Maccarat and 3-card Baccarat) dwarf Blackjack revenues by a factor of 44 in Macau.

Gaming versus Non-Gaming Revenues. According to the Las Vegas Convention and Visitors Authority, Las Vegas generated \$25 billion in non-gaming revenue in 2004 and \$6.8 billion from gaming. Increasingly, visitors to Las Vegas are lured not simply by gambling, but more so by entertainment, fine restaurants, shopping and convention facilities. Success in the non-gaming arena allows casino operators in Las Vegas to better capitalize on the city's increasing appeal as a resort destination for the wider audience of people who do not gamble.

The reality is very different in present day Macau. The average gambler is still a day-tripper from Hong Kong or from nearby Chinese cities in the Pearl River delta. The typical Asian gambler, particularly in Macau, exhibits little interest in entertainment, even when shows are staged free of cost for patrons right on the casino floor. Some casino visitors are so frugal that they often bring their own food and most do not rent hotel rooms. They spend "an average of just 1.26 days in the territory — and even that average is inflated by the many Hong Kong residents who work in Macau Monday through Friday and go home on weekends” (The New York Times, 2008).

Given these illustrative differences in preferences and behavior between customers in Asia (particularly Macau) and those in the Western countries, executives from the Western countries desirous of operating in Asia will have to dramatically alter their managerial mindset. Marketing to gaming customers in Asia will inevitably entail a departure from the marketing strategies 
commonly used to woo gamblers in the West. Toward this end, we shall highlight some of the key components of the adaptations needed to thrive in the Asian marketplace.

\section{MARKETING IN ASIAN GAMING JURISDICTIONS}

We shall use the TROPICS framework developed by Kale (2008) to discuss marketing practices for Asian casinos. TROPICS is an acronym for seven interconnected content areas that ultimately determine the success of marketing. These areas are: targeting, retention, organization, people, incentives, culture, and systems. Conceptually, this framework is equally applicable to firms operating in Western countries as well as those in Asia; however, when put into practice across various countries, the outcome will be different marketing strategies. Regardless of where this framework is implemented, this systematic approach to strategy formulation ensures consistency and alignment across various elements of strategy. Figure 1 represents the TROPICS framework.

Insert Figure 1 Here

Targeting. If a company was to build a casino in an Asian jurisdiction from scratch, each major decision should be based on the answer to the question, "Who am I trying to attract?" (Spence and Kale, 2006). Casinos often cater to multiple, highly disparate audiences (foreigner versus domestic, high-end clientele versus the grind, etc.) with a range of products and services (composition of table games, private gaming rooms, etc.). Yet, every major element of a firm's marketing strategy rests on the characteristics and potential of the target market(s) served. Many times, particularly in unfamiliar and new jurisdictions, casino management casts a wide net and wants to attract everybody. The result is a bland, unfocused, and disjointed marketing strategy, that offers little by way of sustainable competitive advantage. 
Many Western casino operators are drawn to the high end segments of Asian markets. Most high-end players are managed by a junket operator, who receives commission from the casino for delivering players to a particular property. To retain existing junket operators and to lure new ones, casino management tries to offer a commission higher than the prevailing rates. For example, Melco PBL’s Crown Macau raised commissions to 1.35\% of chip sales (Lam, 2009). The result is an unhealthy escalating competition for premium players that ultimately drags down profits for everyone. This is precisely what is happening in Macau today. Though the high-end (VIP) business accounts for around 70 percent of gaming revenues, it contributes less than 30 percent of the profits (Kale, 2008).

Rather than being swayed by high turnover figures as in the case of the VIP segments, casino operators in Asia would be better served by a need-based segmentation process in order to decide on their target market (Best, 2005; Spence and Kale, 2006). Roger Best (2005) suggests a sequential approach to needs-based segmentation, comprising of seven steps:

- Segment the overall market based on needs of various segments comprising the market.

- Segment identification (identify characteristics that make the segments distinct, e.g., demographics, psychographics, situation, etc.)

- Determine attractiveness of the different segments (growth, competitive intensity, market access, etc.)

- Determine segment profitability.

- Create a "value proposition” and product-price positioning strategy for each chosen segment.

- Create segment storyboards to test the attractiveness of positioning.

- $\quad$ Expand positioning to include all aspects of the marketing mix. 
Systematic targeting is guided by answers to three key questions: "Who is our customer?" "Who would we like your customer to be?” "What would we like to know about our current and aspirational customer?”

Retention. The benefits to organizations of a loyal customer base are numerous. Over the long run, relationship-oriented service firms achieve higher overall returns on their investment than transaction-oriented firms (Kumar, 1999). Customer retention in new gaming markets such as Macau is already proving to be problematic. Over the past five years, the mass market for Macau casinos has grown exponentially in size fueled by the increasing number of visitors from the Mainland. In the words of a senior executive in Macau who requested anonymity: “Assuming the growth in visitors continues, there is plenty of revenue to be had harvesting customers, not cultivating them.” Consequently, the mass market segment in Macau is presently a grossly leaking bucket, with new and expensive promotions needed to entice first-time visitors to a casino property. The VIP market, dependent upon commissions to junket operators, is also unstable. A sound retention strategy is needed, based on answers to the following questions:

- What is our customer retention philosophy?

- How seriously do we value customer relationships?

- Who are we trying to retain?

- How accurate is your understanding of share of wallet and customer lifetime value?

- Do/should we fire customers? When and how?

- How do we split our promotional dollars between activities geared toward customer acquisition and retention?

Organization. This element relates to the way the company is structured. Asian societies tend to be more collectivist in their orientation than Western societies and they exhibit greater power distance (inequality) across individuals (Hofsede, 1991). This has implications for organization 
design. Cultural differences between employees at various levels make organizational design very challenging. Thus, for example, remedies to enhance the customer's experience, such as empowering frontline staff so that they can redress (within reason) customer complaints without further authority, may not be transferable by Western firms to Asian employees without first breaking down power distance perceptions. In designing the organization, the following issues need to be addressed:

- $\quad$ Are we organized in a customer-centric manner?

- How is power distributed across various individuals/divisions/departments?

- How entrenched are the departmental silos?

- How coordinated are the functional stovepipes?

- What is the level of support for frontline employees across various units?

- What is the level of team psychological safety, particularly at the C-level?

- How closely are individual employee goals tied to the company’s overall strategy?

People. Closely tied to issues related to organization are the "people” issues. In most service industries (particularly the hospitality industry), employees are the primary brand ambassadors of the company, and the casino industry is no different. The importance of employees in providing the right customer experience is higher in Asian markets than in Western markets because Asian customer prefer table games featuring live dealers whereas Western customers tend to play automated slot machines which require minimal employee-customer interaction.

Except for the recent downturn, there has always been an acute shortage of skilled croupiers in Macau casinos. It is therefore a major challenge for casino management to recruit and retain capable employees. We suggest that the people issues are best dealt with through sound internal marketing practices (Kale, 2007). 
Internal marketing (IM) is defined as "attracting, developing, motivating, and retaining qualified employees through job products that satisfy their needs” (Berry and Parasuraman, 1992, p.25). In marketing literature, internal marketing refers to two somewhat different yet interrelated kinds of activity, which may be termed as 'customer-focused' and 'employee-focused' (Hales and Mecrate-Butcher, 1994). Customer-focused IM is based on the premise that all employees of the organization are de facto marketers. Contacts between service employees and customers represent “moments of truth” (Carlzon, 1987), where consumer perceptions about quality and service are created. Customer-focused IM seeks to align an organization such that it capitalizes on customer encounters to generate new business (Spence and Kale, 2008).

Employee-focused IM is concerned about marketing or promoting the organization to the workforce. It is based on the philosophy of treating employees as internal customers, and the attendant strategy of shaping job products to employee needs (Berry and Parasuraman, 1992). After a thorough review of extant literature, Kale (2007) suggested ten key IM action points for casino management. These are: (1) Competing for the best people; (2) Becoming the preferred employer; (3) Including employees in the company vision; (4) Knowing the internal customer; (5) Hiring for competencies and service inclination; (5) Training for technical and interactive skills; (7) Providing supportive infrastructure; (8) Fully appreciating employees for work done; (9) Measuring and rewarding strong performance; and (10) Frequent communication across all levels in the organization.

Implementation aspects of these action points have been discussed in Zeithaml, et al. (2006), and are therefore not addressed here. An effective solution to the "people" element will require careful consideration of the following:

- What are our hiring policies?

- How do we ensure cultural compatibility between our organization and our people? 
- How serious are we about on-going skill upgrading?

- What do we do to ensure that our people present the right image and the right experience to our customers?

- What do we do to reinforce employee branding?

Incentives. Whether it is in the West or in Asia, if an employer wants the strongest service performers to stay with the company it must appropriately reward them. Reward systems within the organization need to be consistent with the needs and wants of employees and be aligned with the behaviors needed for service excellence. Berthon, Ewing and Hah (2005) empirically derived five values or utilities that make an employer attractive: interest, social, economic, development, and application.

Interest value refers to creating an exciting work environment where workers are encouraged to be creative and are party to novel work experiences (Berthon et al. 2005). The Japanese philosophy of Kiazen has shown that even assembly line production processes are environments that can encourage teamwork and creativity. The Japanese usage of Kaizen is "to take it apart and put back together in a better way.”

Social value is in reference to creating a happy, fun work environment, characterized by collegial relationships (Berthon et al. 2005). Teamwork can be an effective way of encouraging camaraderie and friendships, which makes the act of working more enjoyable. Other useful means to create social value are public relations activities directed to employees, such as firm sponsored Christmas/New Year's parties and retreats. To counter the negative sentiments created by downsizing, more and more companies are realizing the importance of making the workplace enjoyable for employees (Spence and Kale, 2008).

Economic value refers to remuneration, job security, and promotion opportunities (Berthon, et al., 2005), a broad definition, but all pertaining to employees’ financial well-being, now and in 
the future. In Macau, croupiers at casinos currently earn more than college graduates from universities in Hong Kong. However, a recent survey undertaken by the Macau University of Science and technology revealed that gaming employees did not feel they enjoy Macau's economic boom. Furthermore, the employees did not display much confidence with regard to their jobs being secure. The current downturn in casino revenues and earnings can only exacerbate their fears.

Development value refers to intrinsic rewards, like recognition for job performance, a feeling of self-worth and confidence, and preparing employees for career enhancing experiences. New employee training and on-going training reinforces the firm’s commitment toward an employee, while preparing the employee for career advancement. In labor-starved markets, there is the obvious temptation to have new recruits on the job as quickly as possible. This is often at the expense of training, thus reducing the inherent developmental value a job could offer.

Application value refers to the opportunity to apply one's knowledge and to share it with others in an environment "that is both customer-orientated and humanitarian." The concept of mentorship fits in well with the collectivistic and somewhat paternal culture of Asian societies. Casino organizations should utilize mentorship not only as an effective training mechanism for fresh employees, but also as a means of providing application value to the more seasoned employees.

It needs to be borne in mind that the relative importance of these utilities will vary across countries and often among various groups within a country. Rigorous internal marketing research is recommended before an incentive system is put in place. Also, the incentive system needs to have in-built flexibility so as to accommodate diversity within the needs and wants of the workforce. Attention to the following would help in designing an effective incentive system: 
- How compatible are our reward mechanisms with the organizational culture we are striving to create?

- Are our incentives explicitly tied to customer-related outcome metrics?

- Do we conduct internal market research to determine the right mix of the five types of values or utilities that we offer our employees?

- Do we offer individual or team rewards across different levels?

- How do we balance rewards for short term versus long-term performance?

Culture. Organizational culture has been defined as "the pattern of shared values and beliefs that give the members of an organization meaning, and provide them with rules for behavior in the organization” (Davis, 1985). Organizational culture often reflects the national culture of the organization’s home country (Kale and Barnes, 1992; Johnson and Tellis, 2008). Numerous studies demonstrate stark differences between Western cultures and Asian cultures (cf. Barnlund, 1989; Hofstede 1991). Western casino organizations will, therefore, invariably experience a culture clash with their local employees and customers in Asian countries. Furthermore, if they want to create a customer-oriented, service-oriented organization, they will need to instill a service culture, one "where an appreciation for good service exists, and where giving good service to internal as well as external customers is considered a natural way of life and one of the most important norms by everyone” (Gronroos, 1990, p. 244).

The lead author of this article took a trip to Macau recently to conduct informal interviews with senior executives of the foreign-owned properties in Macau. Each executive was asked if the company had made any attempt to assess its organizational culture and make appropriate interventions. Not one of the fifteen executives interviewed indicated any attempts to measure or modify the organizational culture. Success in a service establishment requires explicit and unequivocal answer to the question, "What are our organization's assumptions and values when it 
comes to service vision, servant leadership, customer treatment and employee engagement/empowerment?” Very often the right answer is embedded within the cultural ethos of a society.

Systems. Systems, as discussed here, refer to the information and communication technologies used by a gaming organization. These systems need to be adapted to the cultural and infrastructural realities of specific Asian markets. For example, even though Singapore is a technologically advanced society, not many customers would prefer a casino communicating with them through e-mail. Casino patrons would be aware that Singaporean politicians disapprove of locals’ gambling and would therefore fear reprisals if easily intercepted communication systems are used by the casino. In communicating with mainland Chinese customers, Internet and e-mail may have little chance of success thanks to the low Internet penetration (just over 10 percent). Communication over cellular phones, on the other hand, would be considerably more effective.

Information systems should gather the right kind of customer data. Where slot machines become the primary generators of revenue (as in the U.S.), gathering information about player gambling behavior is a relatively easy undertaking. Gathering similar data in table-dominant jurisdictions is not as easy. While recent advances such as RFID chips are geared toward more comprehensive and accurate information for table games, it will take some time before the accuracy in customer tracking of table games play approaches that for slot machines.

Information is the raw material with which to design desired customer experiences. Customer delight, an outcome desired across all cultures, is made feasible by being able to convert customer information into customer knowledge or even wisdom. This is possible only if the information is shared freely and generously with all interfacing personnel in real-time. More important, the recipients of the information should be appropriately trained to use the information. 
The transformation of information into knowledge is contingent upon how much attention is paid to six factors. First, casino management needs to decide on what information is required for the business to survive and grow in a customer-centric manner. Once the intent of information has been determined, there needs to be broad-based understanding of what needs to be done with the data that are captured. The third issue relates to standards pertaining to data quality. Poor or ambiguous data can mislead management into serious blunders. Fourth, robust and scaleable business systems need to be put in place in order to convert data into usable knowledge. The fifth factor presupposes an understanding of statistical tools to turn masses of data into actionable customer knowledge. Finally, management needs people to interpret, innovate, and action the knowledge. All too often, casino organizations get seduced by the promises of technology, only to realize that people who can optimally use the technology do not exist within the organization.

\section{IMPLICATIONS FOR PRACTITIONERS AND RESEARCHERS}

This article looked at seven factors that define the marketing strategy of a firm. If Western casino operators are to succeed in Asian gaming jurisdictions, they will need to adapt their customer targeting, customer retention activities, company organization, people, incentive mechanisms, organizational culture, and systems to the nuances of the Asian macro-environment within which they operate. Each of the seven factors will need to consider the cultural, infrastructural, and regulatory differences between the home jurisdiction and the host jurisdiction.

The TROPICS framework provides an easy basis with which to make decisions regarding adaptation or standardization along various aspects of a casino’s marketing strategy. While some adaptations are largely non-negotiable (such as government regulations), others (such as choice of a target market or composition of games) are firm-specific and discretionary. In implementing this framework, perhaps the most difficult adaptation would be with respect to organization culture. However, the complexity of this issue should not deter executives from probing and fine- 
tuning the dimension of culture. If management does not instill service culture in an organization from the very start, all other customer-centric initiatives could easily get derailed.

From the research perspective, there has been no study to date that empirically probes the adaptation-standardization issue within the gaming context. Given the rising importance of the services sector worldwide (Zeithaml, Bitner and Gremler, 2006) and the advent of the experience economy (Pine and Gilmore, 1999), the casino industry provides the ideal setting in which to investigate key issues related to managerial and marketing significance. To make this exercise manageable, researchers could choose one aspect within the TROPICS framework and assess its prevalence and application across diverse jurisdictions. Since the majority of future growth in gaming will come from Asian jurisdictions, new and emerging gaming sites in Asia (such as Macau and Singapore) provide fertile contexts within which to investigate, test, and validate various marketing practices and phenomena.

Relating gambling motivations to the desired customer experience could be one area that will yield interesting insights from a cross-national perspective. One casino executive was quoted in Fortune (2005) as saying, "The difference between Westerners and the Chinese is that for Westerners gambling is about entertainment and calculating probabilities. For the Chinese it's a battle with destiny." This difference in perspective toward gambling would translate into myriad differences in attitudes, behaviors, and satisfaction pertaining to the gaming experience. Uncovering these differences should be of value to both researchers and practitioners.

\section{CONCLUSION}

Asia will account for most future growth in the casino industry. Increasingly, policy makers in Asian countries (as evidenced by Macau and Singapore) are inviting participation of Western casino operators in their territory. However, many Western casino executives appear to have less than the requisite understanding of Asian markets to function effectively in these jurisdictions. 
This article looked at the differences in preferences and behaviors between casino gamblers in Western countries and those in Asia, using Macau as an exemplar. We recommend the TROPICS framework as a convenient tool with which to make marketing strategy decisions for Asian gaming jurisdictions. To facilitate this process, we have raised a series of issues and questions regarding each element of the TROPICS framework that casino senior management needs to answer before deciding on their marketing strategy. In order to better serve Asian markets, there is an urgent need to empirically assess patron behavior and the attendant casino marketing adaptations that will be required to succeed in these markets. 
FIGURE 1. The TROPICS Framework for Casino Market Planning

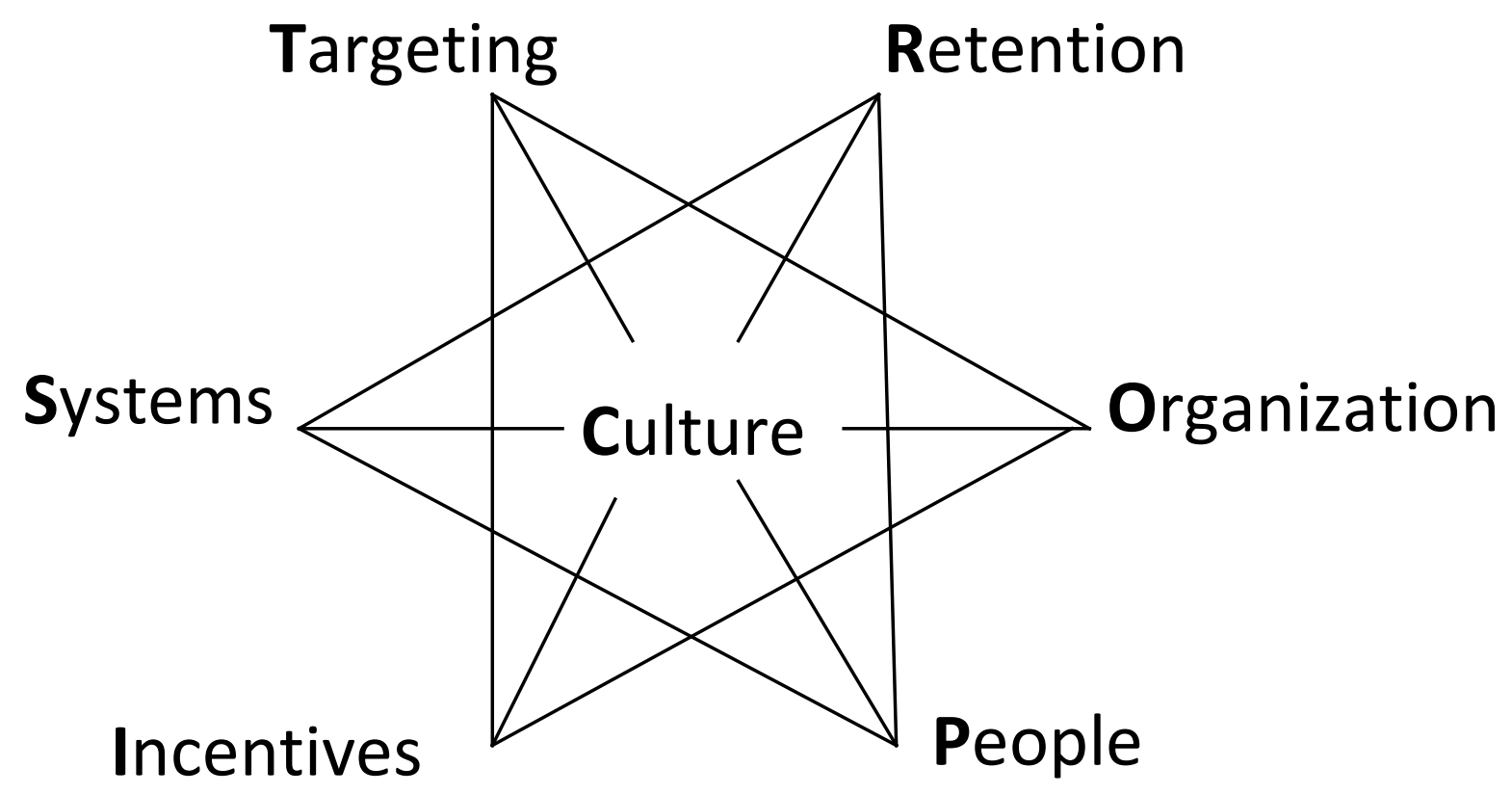




\section{REFERENCES}

Barnlund, D. C. (1989), Communicative Styles of Japanese and Americans, Wadsworth Publishing, Belmont, CA.

Berry L. L. and Parasuraman, A. (1992), “Services marketing starts from within”, Marketing Management, Vol 1 No. 1, pp. 25-34.

Berthon, P., Ewing, M. and Hah, L. L. (2005), “Captivating company: Dimensions of attractiveness in employer branding”, International Journal of Advertising, Vol. 24 No. 2, pp.151-172.

Best, R. J. (2005), Market-Based Management: Strategies for Growing Customer Value and Profitability, $4^{\text {th }}$ edition, Prentice Hall, Englewood Cliffs, NJ.

Carlzon, J. (1987), Moments of Truth, Ballinger Publishing, Cambridge, MA.

Davis, S. M. (1985), Managing Corporate culture, Ballinger Publishing, Cambridge, MA.

Fortune (2005), "The man with the golden gut: Sheldon Adelson, the shrewdest investor in Las Vegas, has a new bet: turning Macau into the biggest, glitziest gambling Mecca the world has ever seen", available at http://money.cnn.com/magazines/fortune/fortune_archive/ 2005/10/17/ 8358041/index.htm/ (accessed 18 June, 2008).

Gaming Inspection and Coordination Bureau (2008), Statistics (2008) available at http://www.dicj.gov.mo/EN/ (accessed 23 June, 2008).

Gronroos, C. (1990), Service Management and Marketing, Lexington, MA; Lexington Books.

Hales, C. and Mecrate-Butcher, J. (1994), "Internal marketing and human resource management in hotel consortia", International Journal of Hospitality Management, Vol. 13 No. 4, pp. 313-326.

Hofstede, G. (1991), Culture and Organizations: Software of the Mind, McGraw-Hill, London, UK.

Johnson, J. and Tellis, G.J. (2008), "Drivers of Success for Market Entry into China and India”, Journal of Marketing, Vol. 72 No. 3, pp. 1-13.

Kale, S. H. (2008), "The practice of casino marketing: What works and what does not work for Chinese customers", paper presented at the Gaming in Asia: Managing for Excellence Conference, Macau SAR, 7-10 April.

Kale, S. H. (2007), “Internal marketing: An antidote for Macau's labor shortage”, UNLV Gaming Research \& Review Journal, Vol. 11 No. 1, pp. 1-11. 
Kale, S. H. and Barnes, J. W. (1992), "Understanding the domain of cross-national buyerseller interactions”, Journal of International Business Studies, Vol. 23 No. 1, pp. 101-133.

Kumar, P. (1999), "The impact of long-term client relationships on the performance of business service firms”, Journal of Service Research, Vol. 2 No. 1, pp. 4-18.

Levitt, T. (1983), “The globalization of markets”, Harvard Business Review, Vol. 61 No. 3, pp. 92-101.

Lam, D. (2009), "Kill the Ills - A Recollection of Events in Macau, 2008”, available at http://www.urbino.net/ (accessed 19 January, 2009).

Pine, J. B., II and Gilmore, J. H. (1999), The Experience Economy: Work is Theater and Every Business a Stage, Harvard Business School Publishing, Boston, MA.

Nevada State Gaming Control Board (2008).Gaming revenue report: April 30, 2008, available at http://www.gaming.nv.gov/documents/pdf/1g_08apr.pdf/ (accessed 22 June, 2008).

Siu, R. and Carmen, C. (2003), "Table Games or Slots? A Strategic Issue Faced by the New Casinos in Macao", paper prepared for the International Conference for the Prospects of the Asia-Pacific Casino Industry, Korea Tourism Research Association, Korea, December.

Siu, R. and Eadington, B. (2008), “Competition, Evolution, and Game Preference in Macau's Casino Industry”, working paper, University of Nevada, Reno, Nevada.

Spence, M. T. and Kale, S. H. (2008), “Optimizing the service value chain: Principles and practices”, Journal of Management \& Organization, Vol. 14 No. 2, pp. 193-206.

Spence, M.T. and Kale, S.H. (2006), "Designing an appropriate brand image and customer gaming experience in Macau: Challenges and opportunities", paper presented at Gaming Industry and Public Welfare, Beijing, China.

The New York Times (2008), "Bigger than Las Vegas? That's Macau's bet”, available at http://www.nytimes.com/2007/08/28/business/worldbusiness/28macao.html?pagewanted =print $/$ (accessed 23 June, 2008).

Zeithaml V.A., Bitner, M. J. and Gremler, D. D. (2006), Services Marketing: Integrating Customer Focus Across the Firm, $4^{\text {th }}$ edition, McGraw-Hill Irwin, New York, NY. 